\title{
Ciencia e ideología en la administración pública: una perspectiva de las Naciones Unidas*
}

\author{
Demetrios Argyriade * *
}

Traducción del inglés, Jorge Ríos Szalay

Señor director, damas y caballeros,

$\mathrm{M}$ e uno a ustedes en este importante Foro sintiendo cierta inquietud y a la vez felicidad. Encontrarme una vez más en esta hermosa ciudad y en este país de gran historia es una fuente de orgullo y alegría. Me siento especialmente honrado por haber sido invitado a disertar por segunda vez en este evento, que tiene lugar una vez al año en la más grande, más prestigiada y más antigua universidad de Latinoamérica. Sin embargo, ello es precisamente lo que constituye el origen de mi ansiedad; espero no defraudarlos.

Hoy lo que propongo que hagamos es que exploremos algunas tendencias contemporáneas de la administración pública que han marcado profundamente el rumbo de la reforma del servicio público y del sector público. Enfocaré la atención en ciertos paradigmas, en su mayoría exógenos, que llegaron a dominar nuestro pensamiento sobre la naturaleza y el alcance del servicio público. Una idea que debo al debate enriquecedor de este Foro, y más precisamente del panel sobre ética, política y administración, es la tensión constante entre ética y política. En la administración, gran parte del desarrollo del pensamiento resulta, pienso yo, de la tensión entre la búsqueda de normas universales para establecer una ciencia administrativa e ideologías que provienen, sobre todo, de modelos contradictorios del hombre y de la sociedad.

\footnotetext{
* Versión escrita de la conferencia especial presentada el 30 de octubre de 2003 en el VIII Foro de Investigación: Congreso Internacional de Contaduría, Administración e Informática, organizado por la División de Investigación de la Facultad de Contaduría y Administración de la UNAM, México, D.F. ** Profesor de la New York University. Correo electrónico: argyriades@un.org
} 


\section{A. La Declaración del Milenio y sus antecedentes}

Permítanme comenzar citando parte de la última proclamación universal de los principios que sustentan la democracia y nuestra civilización. Ésta, sin lugar a dudas, es la Declaración del Milenio de las Naciones Unidas, del ocho de septiembre del año 2000. Esta Declaración, que constituye un hito, fue firmada por ciento cuarenta y siete jefes de Estado y jefes de Gobierno. Su párrafo cuatro dice:

Estamos determinados a establecer una paz justa y duradera en todo el mundo de conformidad con los principios y objetivos de la Carta. Nos entregaremos a apoyar todos los esfuerzos para sostener la soberana igualdad de todos los Estados, la independencia, la resolución de disputas por medios pacíficos y de conformidad con los principios de justicia y derecho internacional, el derecho a la autodeterminación de los pueblos que permanezcan bajo el dominio colonial y la ocupación extranjera, la no injerencia en los asuntos internos de los Estados, el respeto a los derechos humanos y las libertades fundamentales, el respeto por la igualdad de derechos para todos sin distinción de raza, género, lengua o religión, y la cooperación internacional para la solución de problemas internacionales de carácter económico, social, cultural y humanitario.

En el párrafo precedente la Declaración reza así:

Reafirmamos nuestro compromiso con los principios y propósitos de la Carta de las Naciones Unidas, que han probado ser intemporales y universales. Ciertamente, su pertinencia y capacidad para inspirar se han incrementado en la medida en que las naciones y pueblos han incrementado crecientemente su interrelación e interdependencia. ${ }^{1}$

Por supuesto que mucho ha cambiado a lo largo de la vida de la Carta. Revoluciones sucesivas en la ciencia, el pensamiento y la tecnología, aunados al crecimiento de la población, han transformado por completo nuestras vidas y la del medio donde nos desenvolvemos. Y sin embargo, en medio de tan vertiginoso cambio, aún sostenemos los valores tan elocuentemente expresados en la Carta de las Naciones Unidas, que - como seguramente saben - fue elaborada en una conferencia en San Francisco entre los meses de abril y junio de 1945 y entró en vigor el

${ }^{1}$ Resolución A/RES/55/2/8.9.2000. 
24 de octubre, cuando una cantidad suficiente de los Estados miembros la había firmado y ratificado. Necesitamos recordar que Estados Unidos fue el primero en ratificar la Carta, convirtiéndola de esta manera en parte efectiva de la ley aplicable en el país.

Permítanme señalar que la facilidad con la que el Senado de los Estados Unidos aprobó la Carta con una votación de ochenta y nueve contra dos - muy diferente respecto al trato otorgado al Convenio de la Liga de Naciones un cuarto de siglo antes - pudo haberse debido principalmente a la congruencia de sus principios con los pilares fundamentales de la democracia estadunidense. El agudo contraste en las actitudes mostradas, por otra parte, entre 1919 y 1945 sugiere que a estos mismos principios que consideramos "intemporales y universales", y que fueron caracterizados de esa manera por la Declaración del Milenio, no siempre se les ha conferido igual peso, ni han dejado de estar sometidos a retos.

Los principios son antiguos, los encontramos en la Biblia y en el Corán, forman parte del núcleo de las enseñanzas de filósofos chinos y del pensamiento grecoromano, de los estoicos en particular. Su popularidad alcanzó la cúspide en los tiempos de las revoluciones Francesa y Americana, que también fue la Época de las Luces, en Europa y más allá. Permítanme sugerir que su principal logro fue un cierto modelo de hombre, un conjunto de ideas relativas a la naturaleza humana y a las necesidades humanas. La Declaración de Independencia de los Estados Unidos no pudo ser más explícita a este respecto:

Sostenemos como evidentes estas verdades: que todos los hombres han sido creados iguales, que han sido dotados por su Creador de ciertos derechos inalienables y que entre éstos están la vida, la libertad y la búsqueda de la felicidad. ${ }^{2}$

Un contemporáneo de Jefferson, autor de la Declaración, fue el gran poeta alemán Goethe, quien en un célebre poema, significativamente titulado "Das Göttliche" (el quasidios), describe el potencial del hombre, las alturas que, gracias a la virtud de su excepcional naturaleza, el hombre y la mujer pueden alcanzar:

\footnotetext{
${ }^{2}$ Frederick Mosher (1976), American Public Administration 1776-1950: Basic Documents, Nueva York, Holmes \& Meier, p. 9.
} 
Edel sei der Mensch,

Hilfreich und gut!

Denn das allein

Unterscheidet ihn

Von allen Wesen,

Die wir kennen.

Lo cual puede ser traducido libremente de la siguiente manera:

¿Que el hombre sea noble, generoso y bueno! porque eso por sí solo lo distingue de las demás formas de existencia que conocemos

Más adelante Goethe agrega:

Nur allein der Mensch

Vermag das Unmögliche:

Er unterscheidet,

Wählet und richtet;... ${ }^{3}$

Que puede traducirse libremente así:

Sólo el hombre es capaz de soñar lo imposible; él discierne, elige y juzga.

¿El hombre, el soñador noble y racional, nacido en el siglo XVIII? Esto no es exactamente así. El modelo es un tanto antiguo, ha estado forjándose durante más de dos mil años, pero en el siglo XVIII adquiere un sentido político; proporciona las bases para los reclamos contra las autoridades establecidas - seculares o religiosas- y se torna en la fuerza motriz de las sucesivas olas de reformas tanto en el nivel nacional como en el internacional.

Comenzó con la lucha contra el absolutismo, la tiranía y la "larga serie de abusos y usurpaciones" de las que la Declaración de Independencia de los Estados Unidos habla con tanta fuerza; continuó con el establecimiento de un gobierno constitucio-

3 J.W., Goethe "Das Göttliche" en Echtermayer, Deutsche Gedichte, (1954) Dusseldorf A. Bagel verlag, pp. 206-7. 
nal bajo el imperio de la ley. En los Estados Unidos, la separación de poderes fue considerada como un requisito contra la tiranía del ejecutivo, como una manera de garantizar, de hecho, la libertad individual.

\section{B. La expansión de la agenda de los derechos humanos}

Durante el siglo XIX la marcha progresiva continuó con la lucha en contra de la esclavitud, con la expansión del sufragio y con el progreso incansable de la forma de gobierno democrática hasta que, un siglo más tarde y en nuestros días, se convirtió en la más aceptada y probablemente preponderante forma de gobierno en el mundo. Las bases de todo ello eran: esta creencia en la razón, una idea positiva y prometea del hombre y el concepto relacionado de que el gobierno existía únicamente en virtud del consentimiento y sólo para garantizar y promover los derechos humanos y el bienestar humano. Lo que sucedió en los últimos cien años aproximadamente puede ser correctamente descrito como la extensión progresiva del alcance de los derechos humanos y el enriquecimiento del modelo, cuyas raíces aún se encuentran en la tierra del rico pensamiento del siglo XVIII .

No sólo fue redefinido el concepto de derechos humanos para cubrir la igualdad de derechos para todos "sin distinción de raza, género, lengua o religión", en palabras del párrafo cuarto de la Declaración del Milenio, sino que fue hecho también para incluir derechos y prestaciones de seguridad social, lo que agregó un nuevo significado a la "búsqueda de felicidad", así como a la "vida y libertad". Éstos encuentran expresión elocuente en la Declaración Universal de los Derechos Humanos, a la que Eleanor Roosevelt contribuyó de manera significativa. Además de los derechos formales de libertad de expresión y de reunión, esta Declaración, adoptada en diciembre de 1948, reconoció "[...] el derecho al trabajo [...] el derecho a escoger libremente el empleo [...] condiciones de trabajo justas y favorables y [...] protección contra el desempleo."4 También reconoció "el derecho al descanso y al entretenimiento" "el derecho a tener un estándar de vida adecuado para la salud y el bienestar personal y [...] familiar [...]", así como el muy importante derecho a la educación. ${ }^{6}$

\footnotetext{
${ }^{4}$ Universal Declaration of Human Rights, General Assembly Resolution 217(111), 10 de diciembre, 1948, art. 23 .

${ }^{5}$ Ibid., art. 24.

${ }^{6}$ Ibid., art. 26.
} 
Este gran salto tuvo lugar entre las dos guerras mundiales. La diferencia es reflejada en los contenidos e, incidentalmente, a lo largo de los dos documentos de base, el Convenio de la Liga y la Carta de las Naciones Unidas, respectivamente. Ambos documentos proclaman la intención de los signatarios de poner fin a la guerra, alcanzar la paz y la seguridad, promover la cooperación internacional y avanzar en la causa de los derechos humanos y el imperio de la ley. Pero mientras que en la Liga y el Convenio las "altas partes contratantes" eran los gobiernos, contrastantemente "nosotros los pueblos" toma el lugar central en las Naciones Unidas y su Carta. Este enfoque hacia los pueblos ha tenido una influencia determinante tanto en la configuración de las principales áreas funcionales de las $\mathrm{Na}$ ciones Unidas como en la organización cambiante que ha surgido en el proceso del cumplimiento de estas tareas. Mucho más allá que en el Convenio, la cooperación internacional económica y social ha venido a ocupar un rol central en la Carta y en los objetivos que expresa. Este énfasis en el desarrollo recibió un impulso adicional con la descolonización, que casi cuadruplicó el número de miembros de las Naciones Unidas y, sin lugar a dudas, está entre los logros mayores de sus tres primeras décadas. A su vez, esta nueva situación transformó a la Organización de muchas maneras significativas; geográfica y temáticamente alcanzó todos los rincones, abarcando no solamente las oficinas locales y regionales alrededor del mundo, sino también una variedad de temas que se han convertido en objeto ya sea de agencias descentralizadas o de otras agencias especializadas del sistema de las Naciones Unidas.

\section{La Secretaría Internacional}

Esta galaxia de agencias y oficinas alrededor del mundo está adscrita a la Secretaría Internacional, que bien puede ser considerada una de las principales innovaciones institucionales del siglo veinte. Fue un desarrollo lento, que aún debe madurar. En su trabajo pionero de hace unos cuarenta años, el Profesor Georges Langrod hizo referencia a las décadas que iban aproximadamente desde 1860 hasta 1910 "como la era de las organizaciones internacionales." La mayor parte de las organizaciones creadas en ese período eran altamente especializadas (por ejemplo, las relativas a servicios postales, de telecomunicaciones y de pesos y medidas), eran

7 Georges Langrod (1963), La Fonction publique internationale, Leyde, Sythoff. 
muy pequeñas y estaban mayoritariamente formadas por personal del propio país anfitrión. Sin embargo, representaban un comienzo significativo, que señaló el desarrollo de estándares internacionales y estructuras para el arranque y administración sistemática de proyectos multilaterales y regímenes internacionales.

La organización internacional formal recibió un impacto considerable después de la Primera Guerra Mundial con el nacimiento de la Liga de Naciones (Societé des Nations), que también vio el surgimiento del primer secretariado multinacional. Un experimento que fracasó con el apogeo del proteccionismo y la exclusividad nacional, durante la década de 1930, volvió con más fuerza después de la Segunda Guerra Mundial. Con mayor fuerza y de manera más explícita que cualquier disposición del Convenio, las estipulaciones de la Carta de las Naciones Unidas subrayaron claramente "el carácter exclusivamente internacional de las responsabilidades del Secretario General y del personal" (artículo 100); asimismo, indicaron a los empleados "no buscar ni seguir instrucciones de ningún gobierno" y pidieron a los Estados miembros no tratar de influirlos en el cumplimiento de sus funciones.

Como en cualquier secretaría o servicio civil, el personal de las Naciones Unidas divide su tiempo entre aportar apoyo sustancial a los órganos legislativos, asistir a los responsables de la formulación de políticas y llevar a cabo una variedad de tareas operativas, incluyendo actividades tanto para el mantenimiento como para el logro de la paz en diversas partes del mundo. Ni estas funciones normativas ni las obligaciones operativas se han mantenido intactas, ya que han variado en el tiempo en cuanto a su contenido, dirección y peso relativo. Estos importantes cambios han generado la repetida revisión de las estructuras y procesos de la Organización, así como la reconfiguración de las competencias necesarias para llevar a cabo dichas tareas. Esto no es reconocido frecuentemente en los debates públicos, en los que la Organización de las Naciones Unidas es calificada a menudo como inefectiva, rígida, lenta y burocrática.

El que las Naciones Unidas, como cualquier organización, nacional o internacional, tenga fallas es ciertamente indiscutible. Debemos recordar, por otra parte, que acusaciones similares a las lanzadas contra las Naciones Unidas han sido dirigidas a organizaciones en el nivel nacional, siendo la fuente la misma: los detractores del "big government", del "Estado del bienestar" y de la burocracia.

Pero aún hay más: todos los servidores públicos se debaten entre demandas contradictorias: las presiones por cumplir con órdenes y exigencias de corto plazo a 
menudo insistentes, por un lado, y las preeminentes demandas de profesionalismo del servicio público basado en estándares de excelencia y una noción del interés general, por el otro. No obstante, en una medida mucho mayor que la de sus contrapartes nacionales, los servidores públicos internacionales trabajan en un medio altamente volátil y diversificado. Atrapados en medio de un forcejeo, tienen que reconciliar la visión de un mundo y civitas humana que abarca dos mil años con provisiones de la Carta y la necesidad de reconocer y lidiar con las numerosas limitaciones que tienen para impulsar la agenda global en un mundo imperfectamente globalizado. En el nivel internacional las fuerzas centrífugas de los propósitos nacionales se afirman con mayor fuerza que los grupos de interés y de cabildeo de cualquier país en particular. Esto genera que los estándares de excelencia así como el interés general en el nivel internacional sean mucho más difíciles de definir y articular. Las estrategias globales para tratar con asuntos de largo plazo de carácter global requieren más tiempo para ser solucionadas e implementadas.

Estos problemas no son nuevos; sin embargo, se han agravado con la embestida a los gobiernos que tuvo su apogeo al comienzo de los años noventa, pero que aún tiene que apaciguarse. Estos vehementes ataques han venido de la derecha radical y han sido reproducidos, con mayor fuerza, en el nivel internacional. El hecho de que la Organización de las Naciones Unidas, mucho más que el Banco Mundial, el Fondo Monetario Internacional $\mathrm{u}$ otras organizaciones internacionales, haya sido especialmente atacada es difícilmente sintomático; porque lo que realmente está en juego no es el costo-efectividad de las Naciones Unidas, o cualquier otra organización pública, sino el alcance del dominio público, nacional o internacional.

Como producto de la guerra y de los primeros años de la posguerra, la Carta de las Naciones Unidas refleja algunos de los principios e ideales de las agendas de la posguerra tanto del Estado del bienestar como para el desarrollo. Representa de manera clara el esfuerzo doble de asegurar una paz duradera y construir un nuevo orden mundial en el que los beneficios del progreso estén distribuidos ampliamente alrededor del globo y no reservados para tan sólo algunos cuantos. Esto daba cuenta del ámbito de la función de las agendas de las Naciones Unidas y para el desarrollo, las cuales abarcaban la totalidad de las preocupaciones socioeconómicas y ambientales, pero enfocadas en particular en las necesidades de los menos privilegiados y de los pobres. Esto implicaba la intervención del Estado para dirigir y corregir las fallas del mercado donde se dieran. El blanco de la derecha radical, en las pasadas dos décadas, han sido losfracasos del gobierno, ya sean percibidos 
o reales, pero el ataque ha sido contra la gobernabilidad, nacional o internacional. A pesar de algunos halagos hipócritas que apuntan a lo contrario, el imperio de la ley es cuestionado, en particular el de la ley internacional. ${ }^{8}$ Conceptos tales como servicio público e interés público también son atacados o sumariamente rechazados. La teoría de la elección pública, un producto de este periodo, se adhiere a esta posición. Sus dogmas fundamentales pueden ser resumidos de la siguiente manera:

- En primer lugar, la elección pública es simplemente un agregado de preferencias individuales;

- En segundo lugar, los individuos son básicamente impulsados por una conducta económica, " racional", avariciosa, individualista, de maximización de ganancias; $y$

- En tercer término, los representantes políticos elegidos, así como los funcionarios o burócratas se apegan a este patrón general, que rige tanto los mercados como la política, las esferas privada y pública e incluso la voluntaria. ${ }^{9}$

Para el servicio público ciertamente, pero también para el interés público e incluso para la misma democracia, sería problemático encontrar una base sólida en la teoría de la elección pública.

\section{Un nuevo modelo de hombre}

En el origen de todo hay un modelo distinto de hombre. A pesar de que ha sido expresado en la literatura desde los diálogos de Platón, con Sócrates refutándolo, ${ }^{10}$ toma un giro radical en nuestros días, en el sentido de que rechaza la totalidad de los supuestos que tienen que ver con la naturaleza y la conducta humanas en las que se apoyó el progreso hacia la democracia, el estado de derecho, el Estado del bienestar y la difícil pero necesaria construcción de un orden internacional centra-

\footnotetext{
${ }^{8}$ Karl Peter Sommermann (2001), "The Rule of Law and Public Administration in a Global Setting", en Interim Report to the International Congress of Administrative Sciences, Atenas del 9 al 13 de Julio, 2001, p.2.

9 Barry Clark (1998), Political Economy: a Comparative Approach, 2a ed., Westport Conn., Praeger, pp.109 et seq.

${ }_{10}$ Principalmente en La República, donde el argumento refutado es el propuesto por Trasímaco.
} 
do en las Naciones Unidas. Un artículo muy reciente de Richard J. Stillman II resumió algunos de los rasgos sobresalientes de este sistema de creencias radicales de rechazo, en lo concerniente al gobierno:

El mundo dentro del gobierno, de acuerdo con esta tradición de reforma, está poblado por individuos egoístas, meramente interesados por su propio beneficio, no por el beneficio colectivo ni por el bienestar de la sociedad. Es un mundo darwiniano de supervivencia de los empresarios más aptos con los apetitos de voraces depredadores que no sólo se devoran entre sí, sino que se tragan al público (ustedes y yo); un mundo en el que se imponen impuestos cada vez más altos. Esto, a su vez, reduce al sector privado, donde la "verdadera" productividad y la riqueza comunitaria son generadas. Así, los teóricos de la elección pública se concentran principalmente en las maneras de ahorrar, limitar, reducir y hasta eliminar dependencias u organismos gubernamentales a través de la imposición de una variedad de incentivos de mercado para inducir competencia interna o externa. ${ }^{11}$

Las implicaciones de esta visión son de largo alcance. Obviamente, el espíritu público, el respeto por el medio ambiente, la tolerancia, la equidad, la igualdad, la solidaridad y la responsabilidad compartida, recientemente destacados en la Declaración del Milenio, no tienen cabida en este "nuevo" sistema de valores, en el que "libertad" y " democracia" coexisten difícilmente con el darwinismo social. No obstante, hasta el concepto de un orden internacional basado en el respeto por la ley, el consenso, el compromiso y la convivencia de naciones, es difícil de conciliar con este otro enfoque y modelo de conducta humana. En defensa del primero, se puede argüir que, en una medida mucho mayor que el segundo, representa una mezcla de idealismo y realismo, totalmente confirmada por la experiencia de los tres o cuatro últimos siglos. Y aunque se adhiere a la visión de un mundo más perfecto, también acepta las "realidades" del presente y el recurso a la guerra como "ultima ratio regum." 12 Asimismo, enseña moderación en la búsqueda del poder, precisamente considerando las muchas limitaciones y restricciones que rodean al indignante uso de la fuerza, por más "abrumador" que sea. Su apoyo al respeto del imperio de la ley recalca inter-alia la necesidad de consistencia, coherencia y continuidad en las relaciones entre y dentro de las naciones.

\footnotetext{
${ }^{11}$ Richard J. Stillman II (2003), "Twenty-First Century United States Governance: Statecraft as Reform Craft and the Peculiar Governing Paradox It Perpetuates" en Public Administration 81(1):33. Véase también Mark Bevir y R.A.W. Rhodes, "Searching for Civil Society: Changing Patterns of Governance in Britain" en el mismo volumen, dedicado a "tradition of governance: history and diversity", especialmente p. 57.

12 "El último recurso (razón) de los reyes": inscripción latina en las armas de los reyes de Francia.
} 
Estos principios subyacentes, de hecho, datan de largo tiempo atrás: fueron propuestos por primera vez en el Tratado de Westphalia de 1648, después de la Guerra de los Treinta Años, y han sido reiterados en múltiples ocasiones, notablemente en el Convenio de la Liga de Naciones, después de la Segunda Guerra Mundial, y más recientemente en la Declaración del Milenio de las Naciones Unidas, en septiembre de 2000. Estos principios incluyen el respeto por el derecho internacional y las obligaciones de los tratados (pacta servanda sunt); respeto por la igualdad soberana y la integridad territorial de los Estados naciones; y la no injerencia en asuntos domésticos de los mismos. Aunque, en consistencia con estos principios y prácticas democráticas, están a favor de la regla mayoritaria, también establecen límites que buscan abortar los riesgos de la "tiranía de las mayorías" y promover el diálogo, la moderación y el compromiso.

Los eventos dramáticos y los escándalos de los pasados tres años ponen en evidencia la clara sabiduría de estos principios, y, en general, la pertinencia del enfoque que representan al abordar tanto los temas domésticos como los globales. En contraste con lo anterior, los modelos de conducta humana que derivan de la elección pública y los lineamientos para la acción correspondientes pasan del "debemos" al "podemos" y de la visión de un mundo de equidad e igualdad a uno donde sólo el más apto sobreviva. Emulando "la única y mejor manera" y las prerrogativas de los gerentes en contra de cualesquiera otras visiones, este enfoque doctrinario en administración y política ha dado lugar a una actitud contraria al diálogo, hostil a cualquier intento de restringir o circunscribir los poderes de la alta gerencia, impaciente con el desacuerdo, intolerante de la diversidad y, en última instancia, no fácilmente reconciliable con la democracia y sus procesos. ${ }^{13}$

Esta actitud, que llegó a la cúspide durante la década de 1930 y que todavía prevalece ampliamente, ciertamente no es nueva, pero pocas veces desde entonces ha sido manifestada con tal convicción y fuerza en los niveles más altos tanto administrativos como políticos. Aunque dicha actitud puede provenir de las más viejas y prevalecientes tradiciones en la ley, la ciencia política y la administración pública, debe ser tomada seriamente y no puede ser desechada como una mera moda pasajera.

${ }^{13}$ Larry D. Terry (1998) "Administrative Leadership, Neo-manageriation and the Public Management Movement”, Public Administrtion Review 58(3): 194; y Paul Light (1997), The Tides of Reform:Making Government Work, 1945-1995 New Haven, CT, Yale University Press. 


\section{E. ¿Una nueva ciencia de la administración?}

En el nivel administrativo, esta visión está representada por la "nueva gerencia pública" y su variante estadunidense, el "movimiento de reinvención del gobierno". Sus partidarios han buscado representar su surgimiento como una fase de la evolución de las instituciones humanas y una necesidad histórica. ${ }^{14}$ Estas aseveraciones han sido combinadas con pretensiones de cientificidad de la nueva gerencia pública frecuentemente expresadas en la forma de "principios irrefutables y de prescripciones de 'qué hacer' y 'qué no hacer' para gerentes públicos creativos..."15

Los principios en cuestión han sido tomados como axiomáticos. El profesor Ferrel Headdy los describió como "representativos del más reciente impulso para desarrollar una ciencia de la administración con principios de validez universal." " . No puede negarse que, a pesar de su alcance, la nueva gerencia pública sigue siendo esencialmente el producto de una cultura administrativa singular, de una tradición de derecho común, y de un conjunto de circunstancias que en el mejor de los casos son particulares de una porción muy reducida de la población mundial.

El rol desempeñado por las firmas privadas de consultoría administrativa en la difusión del evangelio de la nueva gerencia pública ha sido ampliamente documentado. Surgió en el despertar del torrente del outsourcing y la privatización, que han marcado las reformas del sector público en varias partes del mundo, incluyendo países en desarrollo. Estos consultores en administración, que constituyen una creciente industria de la década de 1990 y aún de nuestros días, ${ }^{17}$ influyeron

\footnotetext{
14 Owen E. Hughes (1998) Public Management and Administration: An Introduction, segunda edición, Nueva York: St. Martin's Press, p.242; Owen Hughes afirma: "El modelo tradicional de administración es obsoleto y ha sido reemplazado en forma efectiva por un nuevo modelo de administración pública. Este cambio representa un cambio de paradigma de un modelo burocrático de administración a uno de mercado cercanamente relacionado con el del sector privado. La reforma administrativa significa una transformación no sólo de la administración pública, sino también de las relaciones entre el mercado y el gobierno, el gobierno y la burocracia, y la burocracia y la ciudadanía".

15 Paul G. Thomas (2000), "Mintzberg on Public Management”, en Henry Mintzberg y Jacques Bourgault (Eds.) Managing Publicly, Toronto, Ontario, IPAC, pp. 146-156.

16 Ibid.

${ }^{17}$ Gerald E. Caiden y Naomi J. Caiden (2002). "The Erosion of Public Service" ASPA National Conference, Phoenix, Arizona, marzo 2002. (Van Riper Panel). Ver también J.S. Nye (2001), "The Best \& the Brightest you show in the Public Service" en International Herald Tribune, agosto 24, 2001, Op. Ed. Page.
} 
poderosamente en el contenido, la dirección, e incluso el estilo y lenguaje de las reformas. ${ }^{18} \mathrm{Su}$ presencia y prevalencia explican hasta cierto punto la naturaleza de las transferencias de políticas ${ }^{19}$ y las tendencias hacia el isomorfismo - coercitivo o mimético - que han caracterizado a las reformas en los países en desarrollo durante las pasadas dos décadas. ${ }^{20}$ También explican discutiblemente la medida de "venta difícil" y las pretensiones exageradas con que frecuentemente se expresaron las propuestas de reformas, en contraste con los escasos resultados reales finalmente obtenidos. C. Pollitt explica este fenómeno:

La reputación de la consultoría gerencial reposa en una interacción exitosa, generalmente de limitada duración [...] Las dificultades surgidas más adelante pueden ser minimizadas atribuyéndoselas a una "deficiente implementación". ${ }^{21}$

Siendo deliberadamente pragmáticos, los defensores de la nueva gerencia públi$c a$ - consultores en administración, en su mayoría, más algunos académicospromovieron el modelo "Nueva Zelanda" o modelo "de mercado", prestándole a menudo poca atención a la cultura y al entorno. Para hacerlo atractivo lo presentaron como un modelo de alcance universal, "nuevo" y "de vanguardia"; el término nueva gerencia pública transmitía precisamente esa impresión, pero en realidad el vocablo es un nombre inapropiado: la nueva gerencia pública difícilmente es nueva, no es específicamente pública, está primordialmente inspirada en el sector privado y, aunque es claramente "tecnocrática", también está anclada en la política de la elección pública y en la economía del lado de la oferta. Esto es ampliamente reconocido; de hecho, podría argumentarse que tiene toda la apariencia de una ideología de fin du siecle. Es una descendiente lineal de la administración científica que cuenta con todos los recursos que una vez prestaron apoyo al avance del taylorismo: la fe implícita en la tecnología como la fuerza impulsora del progreso; el determinismo histórico expresado a través de la creencia en la irreversibilidad de las tendencias actuales principalmente en una dirección, la de la globalización, el triunfo de los mercados y la convergencia de valores.

\footnotetext{
18 Christopher Pollitt (2001), op. cit:; Paul G. Thomas (2000) op. cit.

19 Karen Mossberger \& Harold Wolman (2003) "Policy Transfer as a Form of Prospective Policy Evaluation: Challenges \& Recommendations" en Public Administration Review, Vol. 63, No. 428-440.

${ }^{20}$ Pollitt, op.cit. pp. 937-938.

${ }^{21}$ Ibid., p. 943.
} 


\section{F. Sus antecedentes}

El componente gerencial se remonta al movimiento de ingeniería de los albores del siglo $\mathrm{XX}^{22}$ y el aporte de F.W. Taylor a la eficiencia y productividad de la industria americana. De ahí el énfasis en el "deconstruccionismo" y la "reingeniería"; la defensa supuestamente científica de soluciones del tipo de "la única y mejor manera" (el "una talla le viene a todos" de nuestros días); la representación de las organizaciones como piezas de maquinaria; la proclividad a ver todos los problemas de administración esencialmente en términos técnicos y económicos; la predilección por el adelgazamiento de las estructuras y el "recorte de la gerencia"; y, finalmente, la preferencia por los "caminos difíciles", recalcando el incremento de la autoridad para la gente con autoridad y la "disciplina" para los empleados. ${ }^{23}$

Haciendo memoria del nacimiento y desarrollo del movimiento de la administración científica, necesitamos recordar queTaylor y Fayol, su contemporáneo y opuesto en Francia, fueron ingenieros; que la audiencia a la que se dirigían y su campo operacional era el sector industrial y que sus objetivos estaban enfocados a aumentar la productividad a través de mejores organizaciones y técnicas más efectivas. Su notable éxito, durante las primeras dos décadas del siglo XX, se debe en gran medida a la aplicación de métodos cuantitativos a la organización del trabajo en las plantas industriales, así como a la expansión y fermento intelectual de la profesión de ingeniería en esos días. "La profesión estaba en el proceso de adquirir auto-conciencia ocupacional. Una nueva generación de ingenieros aspiraba a definir la relación de la profesión con la sociedad de una manera que incrementara significativamente el estatus de sus miembros. Las implicaciones más amplias de las [...] ideas de Frederick Taylor contribuyeron a generar una visión ingenieril integral del mundo [...]". ${ }^{24}$

\footnotetext{
${ }^{22}$ Daniel Nelson (1980), Frederick Taylor and the Rise of Scientific Management, Madison, Wisconsin, University of Wisconsin Press.

${ }^{23}$ Linda DeLeon (1998), "Accountability in a 'Reinvented Government", en Public Administration 76(3). ${ }^{24}$ William E. Akin (1977), Technocracy and the American Dream, Berkeley, University of California Press, p. 5; ver también F.W. Taylor "The Principles of Management" y Henri Fayol "General Principles of Management" en H.F. Merrill (Ed.) Classics in Management, 2a. ed., 1970, Nueva York, American Management Association, pp. 72-103 y 189-213.
} 
El ambiente económico y social en el que fueron sembradas las semillas del taylorismo bien pueden explicar la velocidad con la que fue propagado, su alcance significativo y los intentos de aplicarlo en otros campos relacionados. No puede ser ignorado que a principios del siglo XX todavía no se presenciaba una fuerza laboral bien organizada, articulada y vigorosa. Cuando la situación cambió, durante los años treinta y aun más en los cuarenta, cincuenta y sesenta, el taylorismo y los sistemas de creencias a él afines perdieron su atractivo. El empleo total, el triunfo de la democracia y la derrota del fascismo contribuyeron a ello; también explican en buena parte el surgimiento y rápido progreso del movimiento de las relaciones humanas durante esas cuatro décadas.

En verdad, dicho movimiento representa el resultado de la invasión de los centros de trabajo por psicólogos y antropólogos sociales. No es sorprendente que sus instrumentos y métodos de estudio diferían de los empleados por los ingenieros; asimismo, el objeto de su atención y la dirección de su investigación se alejó de lo que había sido el foco de interés de la administración científica: del entorno físico y el proceso de producción, el foco cambió drásticamente a ser el grupo humano en el trabajo. Aún más, el objetivo cambió de la medición del tiempo y los movimientos físicos a la evaluación de las necesidades sociales o de afiliación y psicológicas de la gente en el lugar de trabajo. Ciertamente, en una época de prosperidad con movimientos sindicales fuertes que se beneficiaban de las condiciones de empleo relativamente total, la conservación y motivación del personal emergieron como preocupaciones primarias tanto de la empresa privada como del sector público. Esta transformación gradual del ambiente laboral, sin embargo, también produjo una reevaluación positiva del factor humano en el trabajo; realmente una nueva perspectiva de las dimensiones sociopsicológicas del empleo y sus efectos en la naturaleza humana. Los títulos de los libros escritos en esta época son reveladores a este respecto: ${ }^{25}$

\footnotetext{
${ }^{25}$ C. Argyris (1957), Personality and Organization, Nueva York, Harper; W.G. Bennis (1966), Changing Organizations, Nueva York, McGraw Hill; W.G. Bennis W.G. y P.E. Slater (1968), The Temporary Society, Nueva York, Harper \& Row; N.M. Bradburn y D. Caplovitz (1965), Reports on Happiness, Chicago, Aldine; R.D. Cantril (1965), The Pattern of Human Concerns, New Brunswick, N.J. Rutgers U.P.; F. Herzberg (1966), Work and the Nature of Man, Cleveland, World Publishing Co.; D. Katz y R.L. Kahn (1966), The Social Psychology of Organizations, Nueva York, John Wiley \& Sons; R.L. Likert (1967), The Human Organization, Nueva York, McGraw Hill; D. McGregor (1960), The Human Side of Enterprise, Nueva York, McGraw Hill; A.H. Maslow (1954), Motivation and Personality, Nueva York, Harper; P. Selznick (1957), Leadership in Administration, Evanston, IL, Row Peterson; V.H. Vroom (1964), Work and Motivation, Nueva York, Wiley.
} 
- Personalidad y organización

- El cambio en las organizaciones

- La sociedad temporal

- Reportes sobre la felicidad

- El patrón de las preocupaciones humanas

- El trabajo y la naturaleza del hombre

- La psicología social de las organizaciones

- La organización humana

- El aspecto humano de la empresa

- Motivación y personalidad

- Liderazgo en la administración

- Trabajo y motivación

\section{G. La embestida gerencial}

Todo esto iba a cambiar hacia el fin de siglo. Sin embargo, sugestivamente, cuando ocurrió este cambio no fue principalmente por el trabajo de académicos o practicantes de la administración pública, sino por el de ejecutivos de negocios, consultores en administración privada y economistas. Comenzó con el entorno de la administración pública; las tareas que durante varias décadas desde el fin de la Segunda Guerra Mundial habían sido vistas como las labores centrales del gobierno, como el dominio del Estado y los objetivos supremos de la administración del desarrollo, eran ahora cuestionadas. Inicialmente, la causa de este cambio en los acontecimientos pudo haber sido la recesión generada por la crisis energética de mediados de los setenta. No obstante, lo que comenzó como esfuerzos de recortes de presupuesto y mejora del mantenimiento del Estado tomó otra forma con el ascenso al poder de líderes ultra conservadores como Thatcher y Reagan. Pronto la economía keynesiana y la estructura completa del Estado del bienestar fueron atacadas. Ambas habían sido factores poderosos en moldear la evolución tanto de la teoría como de la práctica de la administración pública después de la Segunda Guerra Mundial.

Ya durante los años sesenta una nueva escuela de pensamiento había tratado de cambiar el foco de atención del mundo interno de las organizaciones hacia su entorno cambiante. El nombre "teorías de contingencia", por el que ha sido conocida, llamó la atención sobre la importancia de las consideraciones pragmáticas, las cuales diferían de manera considerable de un caso a otro. Contrastantemente, 
lo que pronto siguió en los ochenta y noventa fue una ofensiva concertada, profundamente ideológica en su naturaleza y ciertamente no limitada a un debate académico. No sólo las fronteras, sino también el propio centro y la identidad de la administración pública fueron puestos en duda. En la nueva gerencia pública no existía tal cosa, o al menos eso parecía sugerir su famoso slogan "gerencia es gerencia".

No obstante, no satisfecha con anexar el sector público y convertir lo oficial a las formas del sector privado, la ofensiva de la nueva gerencia pública fue mucho más lejos. En primer lugar, los Estados y los mercados tenían que ser fusionados; en segundo, el imperio de la ley, el proceso justo y la democracia tenían que ser reconsiderados en términos amistosos de negocios y redefinidos a la luz de los supremos principios de la nueva gerencia pública: economía, eficiencia y efectividad. ${ }^{26}$ Otros valores en juego fueron tranquilamente ignorados o desechados. El lenguaje y las metáforas empleadas para "vender" esta visión del mundo revelan el tipo de mentalidad que representa la nueva gerencia pública. Es como si la implosión de la Unión Soviética y el fin de la Guerra Fría hubiesen inaugurado una nueva era, de hecho una nueva religión. Todo lo que existía previamente fue condenado a la obsolescencia. ${ }^{27} \mathrm{El}$ "gerente empresarial" fue ensalzado. "La administración pública" dio paso a "la gerencia pública"; el "gobierno" cedió su lugar a la "gobernabilidad". Ambos sirvieron para enfatizar el rol de las fuerzas del mercado en este nuevo esquema de cosas y para abogar por la participación de accionistas corporativos "en sociedad" con el gobierno.

El "ciudadano" fue convertido en un "cliente". De hecho, se puede decir que esta conversión es una característica esencial del nuevo paradigma. Aunque esto es legítimo hasta cierto punto, en cuanto a que llama a la respuesta diligente y efecti-

\footnotetext{
${ }^{26}$ Este punto fue también argumentado por Lawrence Lynn Jr. en "The Myth of the Bureaucratic Paradigm: What Traditional Public Administration Really Stood For", en Public Administration Review, marzo/abril 2001 61(2), pp. 144-157. Asimismo, fue abordado por David H. Rosenbloom, "History Lesson for Reinventors", en Public Administration Review, marzo/abril, 2001 61(2), pp.161-165. Característicamente, David Rosenbloom concluye que: "La literatura clave del movimiento de la reinvención del gobierno tiene profundas fallas. En primer lugar, no es nada claro si los reinventores saben o no qué es lo que están reinventando[...] Sus conceptos de democracia y su relación con la administración son confusos. Afirman favorecer los valores democráticos; sin embargo al mismo tiempo desacreditan las elecciones, las instituciones representativas y los requerimientos legales para la representación, la participación, la transparencia y la justicia en la toma de decisiones administrativas".

${ }^{27}$ Owen E. Hughes (1998), op. cit.
} 
va a las demandas y expectativas de los ciudadanos, puede ser profundamente desorientador. No sólo cambia un fundamento sólido de derechos constitucionales por la "capacidad adquisitiva" como base de las relaciones entre gobierno y gobernados, sino que trivializa la ciudadanía, colocando a los ciudadanos en una situación desagradable del proceso político; también reduce el alcance de la acción del gobierno, limitándolo, en efecto, a la provisión de servicios a "clientes". Las funciones normativas del gobierno y lo que el profesor Dror describe como "tareas de orden superior" 28 son desdeñadas; la nueva gerencia pública no las considera como preocupaciones primordiales ni siquiera como tareas legítimas para los servidores públicos.

La rápida propagación de la nueva gerencia pública durante las décadas de 1980 y 1990 no puede ser entendida salvo en términos políticos como el auge de fuerzas políticas de la derecha radical y el triunfo del neoliberalismo, el cual traía consigo. Intelectualmente, sin embargo, de manera muy similar al cambio previo de la administración científica al movimiento de las relaciones humanas, representó el producto de la confluencia de eventos y tendencias que alteraron drásticamente el balance de poder de la posguerra, pero también aseguraron el dominio del pensamiento neoconservador en la política y la administración. La economía postkeynesiana reemplazó a la psicología, la sociología y el derecho; el homo economicus desplazó todos los modelos humanistas anteriores como punto de referencia básico.

El cambio ha sido presentado como un sometimiento a las nuevas realidades, como un enfoque pragmático o discutiblemente como una mejor manera de abordar los asuntos de la gobernabilidad contemporánea. Como quiera que ello sea, cabe poca duda de que la forma en que la nueva gerencia pública toma a la economía tiene ramificaciones más amplias. Aunada a su deuda con la teoría de la elección pública, la conversión del ciudadano a "cliente" toma singular importancia; pareciera sugerir que las preferencias individuales, vistas por la nueva gerencia pública, son independientes del entorno social. La sociedad apenas existe. "Esta visión contrasta agudamente con la perspectiva de la mayoría de los sociólogos y psicólogos que enfatizan el rol del condicionamiento social y de la aculturación en el

${ }^{28}$ Y. Dror (2001), The Capacity to Govern: a Report to the Club of Rome, Londres, Frank Cass, p. 63. 
molde de las preferencias individuales." ${ }^{29}$ De acuerdo con Barry Clerk, "el deseo de emular la ciencia natural", atado a la búsqueda de certidumbre, dictó la posición que algunos economistas tomaron. ${ }^{30}$

Sería justo argumentar que esta postura particular no es totalmente carente de contenido ideológico; especialmente en años recientes, le ha añadido apoyo a un notable desaire de los puntos de vista o perspectivas que difieren de las opiniones de la ortodoxia económica. Al igual que ésta, la predilección de la nueva gerencia pública por las recetas tipo "una talla le viene a todos" no ha admitido diversidad, sino que ha apoyado la no ambivalencia de enfoques y ha sido fiel a "la única y mejor manera". Más aún:

ha impulsado metodologías y una mentalidad de base [...] que sostienen que el éxito financiero es el único valor que debe ser considerado, promoviendo soluciones de corto plazo que sean financieramente sólidas de manera inmediata a pesar del hecho de que puedan ocasionar problemas a otros en la organización o a la organización en general en el largo plazo. ${ }^{31}$

Llevada a un extremo, la búsqueda de "resultados por encima del proceso" avalada por la nueva gerencia pública puede acabar no sólo con el imperio de la ley y el proceso justo, no sólo con las normas éticas, sino también con una gran tradición, de más de dos siglos, sobre la cual descansan la convivencia y la paz internacional, los derechos humanos y la democracia.

${ }^{29}$ Clark, B. (1998), Political Economy and Comparative Approach, Westport, CT, Praeger, p. 312.

${ }^{30}$ Ibid.

${ }^{31}$ Kakabadse A, Korac-Kakabadse N. y Kouzmin, A. (2003) "Ethical Values and Behaviours: Comparison of three Case Studies Examining the Paucity of Leadership in Government", en Public Administration, Vol. 181, No. 3, p. 479. 